\title{
An Efficient Viologen-Based Electron Donor to Nitrogenase
}

\author{
Artavazd Badalyan,*당 Zhi-Yong Yang, ${ }^{\circ}$ Bo Hu, Jian Luo, Maowei Hu, T. Leo Liu, \\ and Lance C. Seefeldt* (i) \\ Department of Chemistry and Biochemistry, Utah State University, 0300 Old Main Hill, Logan, Utah 84322, United States
}

\section{Supporting Information}

ABSTRACT: Nitrogenase catalyzes the reduction of $\mathrm{N}_{2}$ to $\mathrm{NH}_{3}$, supporting all biological nitrogen fixation. Electron donors to this enzyme are ferredoxin or flavodoxin (in vivo) and sodium dithionite (in vitro). Features of these electron donors put a limit on spectrophotometric studies and electrocatalytic applications of nitrogenase. Although it is common to use methyl viologen as an electron donor for many low-potential oxidoreductases, decreased nitrogenase activity is observed with an increasing concentration of methyl viologen, limiting its utility under many circumstances. In this work, we suggest that this concentration-dependent decrease in activity can be explained by the formation of a dimer of the radical cation of methyl viologen $\left(\mathrm{Me}_{2} \mathrm{~V}^{\bullet+}\right)_{2}$ at higher methyl viologen concentrations. In addition, viologens functionalized with positively and negatively charged groups were synthesized and studied using spectroscopy and cyclic voltammetry. A sulfonated viologen derivative, 1,1'-bis(3-sulfonatopropyl)-4,4'-bipyridinium radical $\left\{\left[(\mathrm{SPr})_{2} \mathrm{~V}^{\bullet}\right]^{-}\right\}$, was found to support full nitrogenase activity up to a mediator concentration of 3 $\mathrm{mM}$, while the positively charged viologen derivative was not an efficient reductant of nitrogenase due to the high standard redox potential. The utility of $\left[(\mathrm{SPr})_{2} \mathrm{~V}^{\bullet}\right]^{-}$as an electron donor for nitrogenase was demonstrated by a simple, sensitive spectrophotometric assay for nitrogenase activity that can provide accurate values for the specific activity and turnover rate constant under argon. Under $\mathrm{N}_{2}$, the formation of ammonia was confirmed. Because of the observed full activity of nitrogenase and low overpotential, $\left[(\mathrm{SPr})_{2} \mathrm{~V}^{\bullet}\right]^{-}$should also prove to be valuable for nitrogenase electrocatalysis, including bioelectrosynthetic $\mathrm{N}_{2}$ reduction.

$\mathrm{T}$ he biological reduction of $\mathrm{N}_{2}$ to $\mathrm{NH}_{3}$ is catalyzed by the enzyme nitrogenase. The molybdenum-dependent nitrogenase consists of two component proteins (Figure 1a): the molybdenum-iron protein $(\mathrm{MoFeP})$ and the iron protein (FeP). ${ }^{1}$ MoFeP houses two unique cofactors, the electron carrier $[8 \mathrm{Fe}-7 \mathrm{~S}]$ (P-cluster) and the catalytic [7Fe-9S-1Mo-Chomocitrate] (FeMo-co). ${ }^{2} \mathrm{FeP}$ contains a single $[4 \mathrm{Fe}-4 \mathrm{~S}]$ cluster and two MgATP binding sites. During the catalytic cycle, the FeP is reduced by either flavodoxin or ferredoxin (in vivo $)^{3,4}$ or sodium dithionite or reduced methyl viologen (in vitro $)^{5,6}$ and binds two MgATP molecules. Then, FeP transiently associates with the MoFeP and transfers an electron, followed by hydrolysis of two MgATP molecules and dissociation from MoFeP. ${ }^{7}$ The released oxidized FeP is reduced, and the two MgADP molecules are replaced by two MgATP molecules, making FeP ready for another round of $\mathrm{MoFeP}$ reduction. This cycle (called the FeP cycle) is repeated four times to cause the accumulation of four electrons and four protons on FeMo-co as two bridging hydrides and two protons. This four-electron reduced state [called $\mathrm{E} 4(4 \mathrm{H})$ ] releases $\mathrm{H}_{2}$ and binds $\mathrm{N}_{2}$ with a reduction by two electrons. ${ }^{8,9}$ Four more electron/proton delivery cycles must be completed to achieve the reduction of the $\mathrm{N}_{2}$ to two ammonia molecules (eq 1 ). In the absence of $\mathrm{N}_{2}$, hydrides and protons react, and $\mathrm{H}_{2}$ is evolved (eq 2).

$$
\begin{aligned}
& \mathrm{N}_{2}+16 \mathrm{MgATP}+8 \mathrm{H}^{+}+8 \mathrm{e}^{-} \rightarrow 2 \mathrm{NH}_{3}+\mathrm{H}_{2} \\
& \quad+16 \mathrm{MgADP}+16 \mathrm{P}_{\mathrm{i}} \\
& 4 \mathrm{MgATP}+2 \mathrm{H}^{+}+2 \mathrm{e}^{-} \rightarrow \mathrm{H}_{2}+4 \mathrm{MgADP}+4 \mathrm{P}_{\mathrm{i}}
\end{aligned}
$$

Elucidation of aspects of the mechanism of nitrogenase and the application of this enzyme in biofuel and biosynthetic cells are of high interest for chemical conversion and energy-related efforts. This requires an efficient reductant for nitrogenase that does not affect the enzyme activity. In addition, it would be valuable if the reductant showed a large change in its extinction coefficient between its reduced and oxidized forms so that it could be used for spectroscopic studies, and it showed reversible electrochemical behavior at the electrode surface with a low overpotential to support nitrogenase electrocatalysis (i.e., the standard potential difference between the mediator and $[4 \mathrm{Fe}-4 \mathrm{~S}]$ cluster of $\mathrm{FeP}$ of nitrogenase). Most in vitro studies of nitrogenase over decades have utilized the reductant sodium dithionite. While convenient for fixed-time product measurement, sodium dithionite is of limited value in spectroscopic investigations due to its low extinction coefficient and in electrocatalysis due to its irreversible electrochemical reaction at the electrode surface. Alkyl viologens, for example, methyl viologen, represent a sound alternative to sodium dithionite and have been applied as stoichiometric reductants and as electrochemical mediators for enzymes such as hydrogenase, ${ }^{10-12}$ formate dehydrogenase, ${ }^{13,14}$ and CO dehydrogenase. ${ }^{15,16}$

Our recent studies ${ }^{17}$ revealed that methyl viologen is an efficient reductant for nitrogenase (Figure $1 b, c$ ), supporting substrate reduction activity similar to the activity measured

Received: September 12, 2019

Revised: November 3, 2019

Published: November 4, 2019 
a

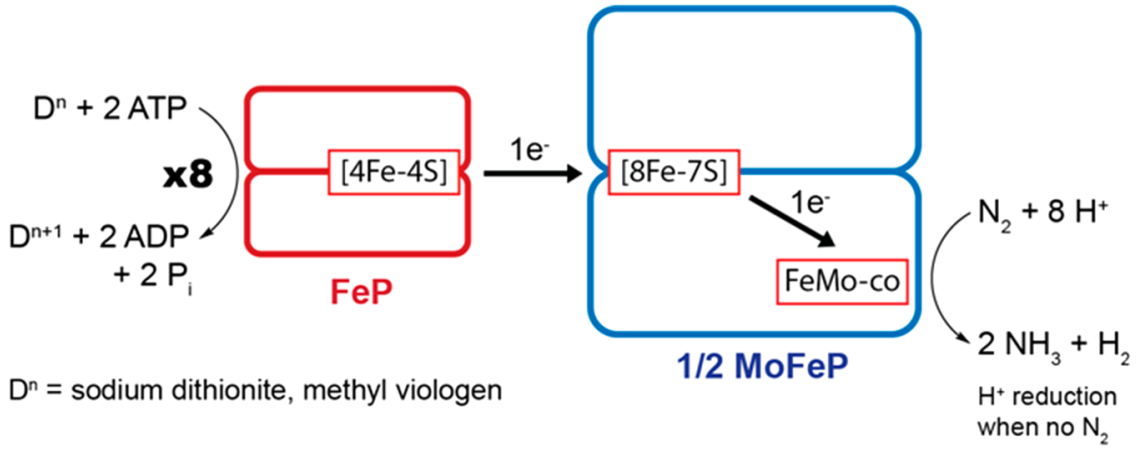

b

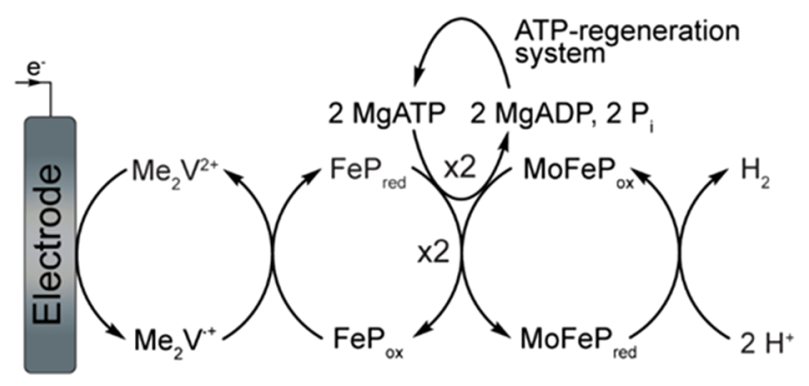

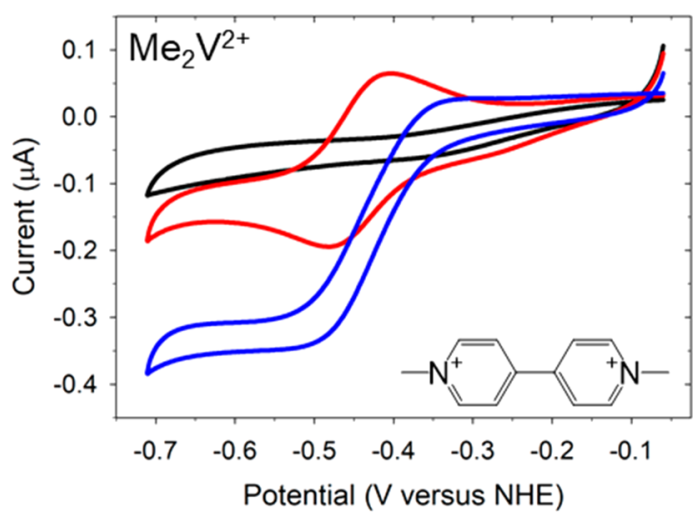

Figure 1. (a) Simplified catalytic scheme for in vitro nitrogenase catalysis. (b) Mediated electrocatalytic system utilizing nitrogenase showcased under argon. (c) Cyclic voltammograms recorded with solutions of activity buffer (black), upon addition of $50 \mu \mathrm{M}$ methyl viologen (red), and then upon addition of the nitrogenase complex (MoFeP:FeP, 1:15, blue). The activity buffer contains $100 \mathrm{mM} \mathrm{MOPS}(\mathrm{pH} 7.0), 6.7 \mathrm{mM} \mathrm{MgCl}, 5 \mathrm{mM}$ ATP, and an ATP regeneration system ( $30 \mathrm{mM}$ phosphocreatine, $0.2 \mathrm{mg} / \mathrm{mL}$ phosphocreatine kinase, and $1.3 \mathrm{mg} / \mathrm{mL}$ bovine serum albumin).

with sodium dithionite. However, the catalytic performance of nitrogenase is observed to be dependent on the methyl viologen concentration. At millimolar concentrations, methyl viologen causes significant inhibition of nitrogenase activity as a reductant in spectrophotometric activity assays ${ }^{5}$ and electrolysis cells. ${ }^{18}$ This effect is not well understood. As a result, most nitrogenase kinetic studies still rely on dithionite. In this Communication, we studied the inhibitory effect of methyl viologen and further report a viologen derivative that can be efficiently used in the millimolar concentration range that enables a high-utility spectroscopic activity assay to quantify the flow of electrons through nitrogenase. In addition, the viologen derivative is useful for electrocatalysis studies with nitrogenase.

The effect of methyl viologen concentration on nitrogenase activity was demonstrated via a spectroscopic study of nitrogenase $(0.4 \mu \mathrm{M} \mathrm{MoFeP}$ and $6 \mu \mathrm{M} \mathrm{FeP})$ and a radical cation form of methyl viologen $\left(\mathrm{Me}_{2} \mathrm{~V}^{\bullet+}\right)$ in the activity assay buffer containing $100 \mathrm{mM}$ MOPS ( $\mathrm{pH} 7.0$ ), $6.7 \mathrm{mM} \mathrm{MgCl}_{2}, 5$ $\mathrm{mM}$ ATP, and an ATP regeneration system (30 mM phosphocreatine, $0.2 \mathrm{mg} / \mathrm{mL}$ phosphocreatine kinase, and $1.3 \mathrm{mg} / \mathrm{mL}$ bovine serum albumin). The mixture led to rapid oxidation of $\mathrm{Me}_{2} \mathrm{~V}^{\bullet+}$ to $\mathrm{Me}_{2} \mathrm{~V}^{2+}$ followed at $606 \mathrm{~nm}$, reflecting the nitrogenase catalytic reduction of protons to $\mathrm{H}_{2}$ under argon (Figure 2a). A typical time curve is shown in Figure $2 \mathrm{~b}$. The rate constant $\left(k_{\text {obs }}\right)$ obtained with different $\mathrm{Me}_{2} \mathrm{~V}^{\bullet+}$ concentrations reveals that increasing concentrations of $\mathrm{Me}_{2} \mathrm{~V}^{\bullet+}$ result in decreasing rate constants $\left(k_{\text {obs }}\right)$ as shown in Figure $2 \mathrm{c}$. The highest value of $k_{\mathrm{obs}}\left(11 \mathrm{~s}^{-1}\right)$ was observed at
$250 \mu \mathrm{M}$ methyl viologen. No significant background process took place in the absence of nitrogenase components.

We sought to understand the origin of the inhibitory effect at higher concentrations of $\mathrm{Me}_{2} \mathrm{~V}^{\bullet+}$. It is known that persistent $\pi$-radicals such as $\mathrm{Me}_{2} \mathrm{~V}^{\bullet+}$ can take part in radical-radical interactions $^{19}$ that result in the formation of a dimer $\left(\mathrm{Me}_{2} \mathrm{~V}^{\bullet+}\right)_{2}$ (Figure 2d). The reported association constant of $\mathrm{Me}_{2} \mathrm{~V}^{\bullet+}$ is $1300 \mathrm{M}^{-1}$. ${ }^{19}$ Figure $2 \mathrm{c}$ (red) shows the development of the dimer as a function of the total $\mathrm{Me}_{2} \mathrm{~V}^{\bullet+}$ concentration, which is consistent with the decrease in $k_{\mathrm{obs}}$ for nitrogenase catalysis.

The dimerization of methyl viologen can increase the formal potential (see the Supporting Information for more details), thereby decreasing the driving force between this mediator and nitrogenase. Our theoretical analysis of the methyl viologen redox couple based on the Nernst equation showed a maximum positive shift of $+30 \mathrm{mV}$ as a result of increasing methyl viologen concentration in the range of $0.05-3 \mathrm{mM}$ (Figure S3). Similar results were obtained experimentally by using cyclic voltammetry (Figure S3). This shift should not have a major effect on nitrogenase catalysis. This suggested that dimerization inhibits the activity of nitrogenase by another mechanism.

In an effort to overcome the inhibitory effect of methyl viologen, we synthesized two viologen derivatives: 1,1'-bis[3(trimethylammonium)propyl]-4,4'-bipyridinium tetrabromide $\left\{\left[(\mathrm{NPr})_{2} \mathrm{~V}\right] \mathrm{Br}_{4}\right\}$ bearing two additional positively charged ammonium groups ${ }^{20}$ and $1,1^{\prime}$-bis(3-sulfonatopropyl)-4,4'bipyridinium $\left[(\mathrm{SPr})_{2} \mathrm{~V}\right]$ bearing two additional negatively charged sulfonic groups. ${ }^{21}$ These derivatives were first tested 


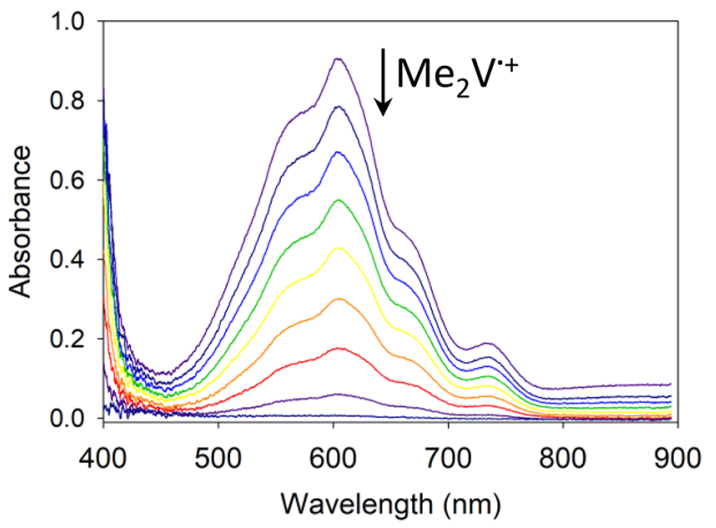

C

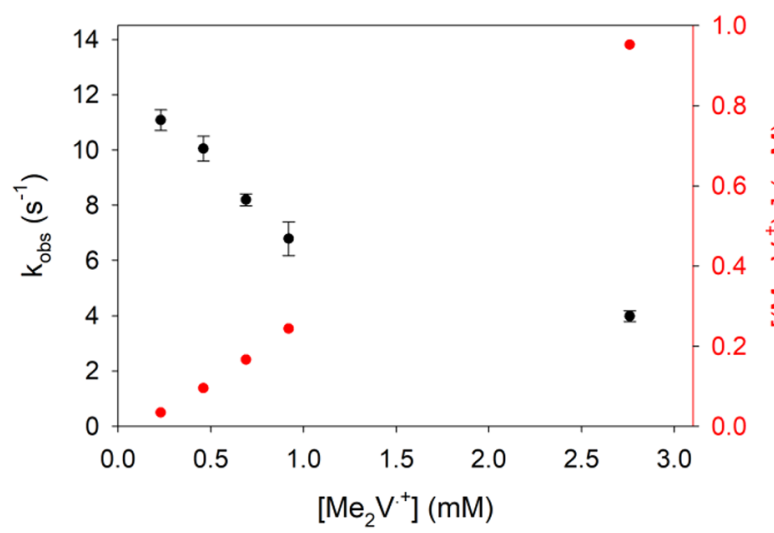

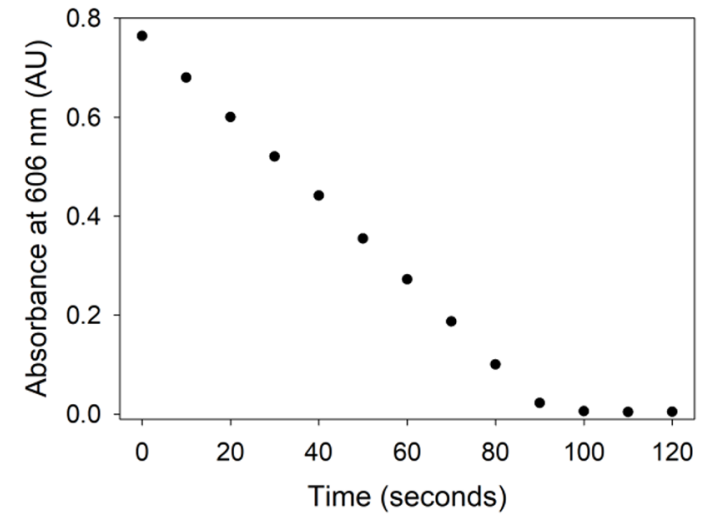

d<smiles>C[n+]1ccc(-c2cc[n+]([Cl+])cc2)cc1</smiles>

Methyl Viologen Cation Radical $\left(\mathrm{Me}_{2} \mathrm{~V}^{+}\right)$<smiles>CN1C=CC(c2cc[n+](C)cc2)C=C1</smiles>

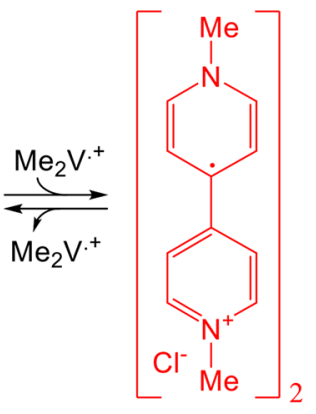

Methyl Viologen Cation Radical Dimer $\left(\left[\mathrm{Me}_{2} \mathrm{~V}^{\cdot+}\right]_{2}\right)$

Figure 2. Methyl viologen cation radical $\left(\mathrm{Me}_{2} \mathrm{~V}^{\bullet+}\right)$ as a reductant in a spectrophotometric activity assay for nitrogenase under argon. (a) Spectrophotometric evidence of the oxidation of $0.45 \mathrm{mM} \mathrm{Me}_{2} \mathrm{~V}^{\circ+}$ by nitrogenase and (b) time course at $606 \mathrm{~nm}$ measured in a cuvette with a 0.2 $\mathrm{cm}$ path length. (c) $k_{\text {obs }}$ vs $\left[\mathrm{Me}_{2} \mathrm{~V}^{\bullet+}\right]$ (black) and calculated $\mathrm{Me}_{2} \mathrm{~V}^{\bullet+}$ dimer concentration (red). (d) Redox transition of methyl viologen to $\mathrm{Me}_{2} \mathrm{~V}^{\bullet+}$ and the dimerization reaction. Conditions: $0.4 \mu \mathrm{M} \mathrm{MoFeP}$ and $6 \mu \mathrm{M} \mathrm{FeP}$ in activity assay buffer $(0.5 \mathrm{~mL} n=3)$.
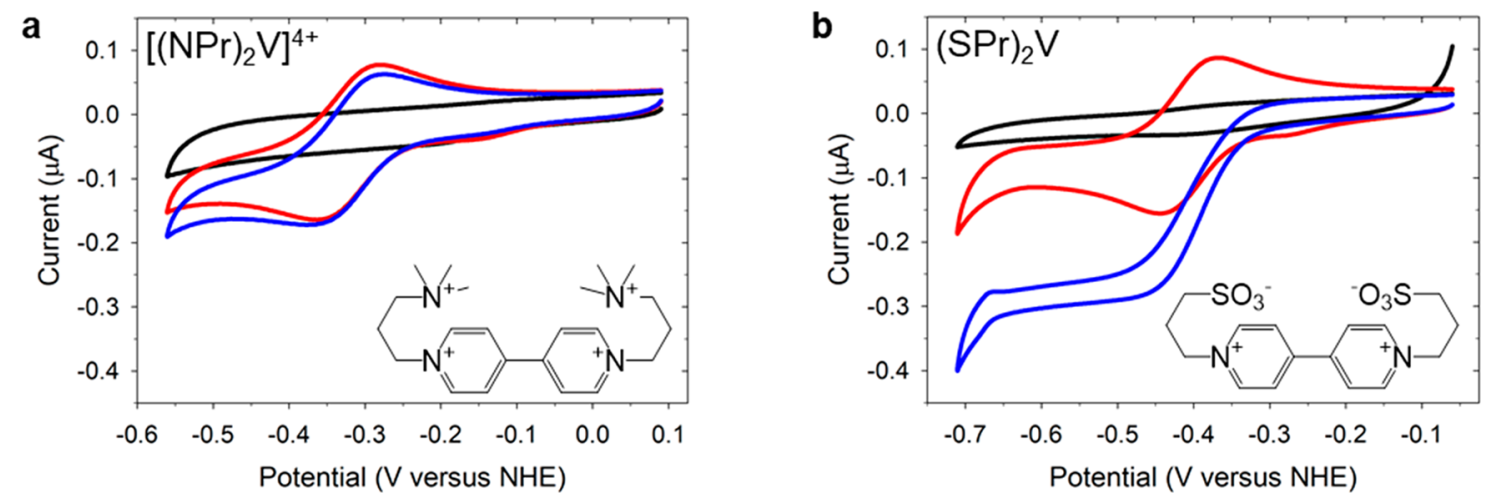

Figure 3. Voltammetric studies of viologen derivatives (a) $(\mathrm{NPr})_{2} \mathrm{~V}^{4+}$ and $(\mathrm{b})(\mathrm{SPr})_{2} \mathrm{~V}$. Cyclic voltammograms were recorded with solutions of activity assay buffer (black), upon addition of $50 \mu \mathrm{M}$ viologen derivative (red), and upon addition of the nitrogenase complex (MoFeP:FeP, 1:15, blue).

using the voltammetric approach. ${ }^{17}$ Cyclic voltammograms were recorded in the activity assay buffer, after addition of the corresponding viologen at $50 \mu \mathrm{M}$ and after the addition of 0.4 $\mu \mathrm{M}$ MoFeP and $6 \mu \mathrm{M} \mathrm{FeP}$ (Figure 3). As shown in Figure 3a, in the presence of $\left[(\mathrm{NPr})_{2} \mathrm{~V}\right]^{4+}$, the current did not change after addition of nitrogenase, reflecting the fact that this derivative does not efficiently reduce nitrogenase $\mathrm{FeP}(-0.4 \mathrm{~V}$ vs NHE, measured at $\mathrm{pH} 8$ in the presence of MgATP $),{ }^{22,23}$ likely due to its higher standard reduction potential $(-0.32 \mathrm{~V}$ vs NHE). The standard potential of $(\mathrm{SPr})_{2} \mathrm{~V}(-0.40 \mathrm{~V}$ vs $\mathrm{NHE}$ ) was $40 \mathrm{mV}$ more positive than that of methyl viologen, but it was sufficient to reduce nitrogenase (Figure $3 \mathrm{~b}$ ).

The rate constants in the presence of $\mathrm{Me}_{2} \mathrm{~V}^{2+}$ and $(\mathrm{SPr})_{2} \mathrm{~V}$ were 13 and $12 \mathrm{~s}^{-1}$, respectively, with the corresponding viologen at $50 \mu \mathrm{M}$. $k_{\mathrm{obs}}$ was determined using eq 3 derived for nitrogenase electrocatalysis ${ }^{17}$ 

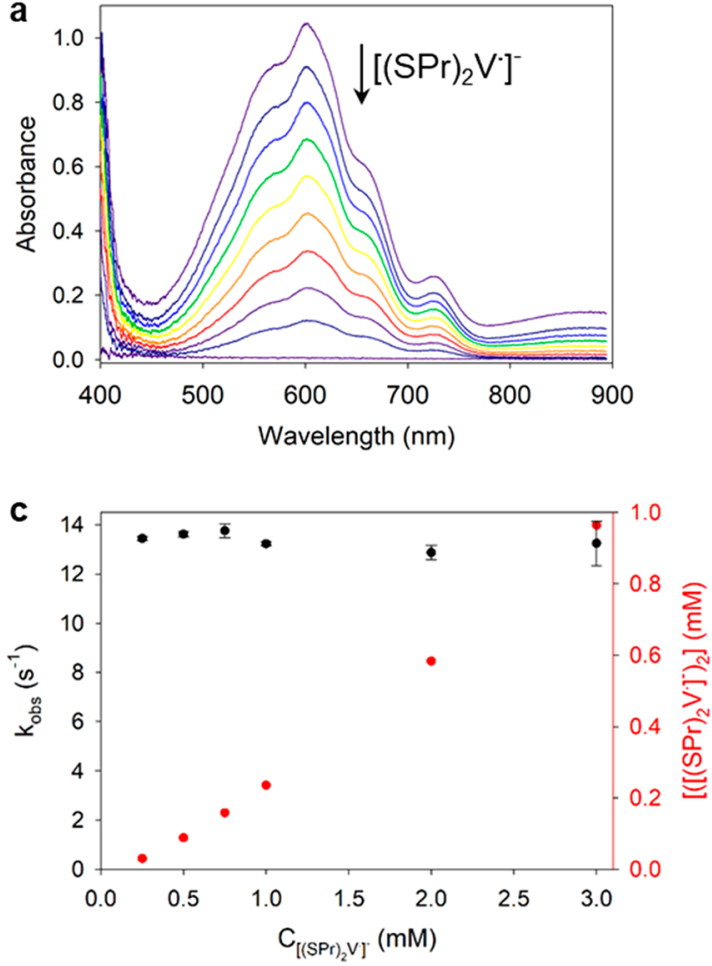
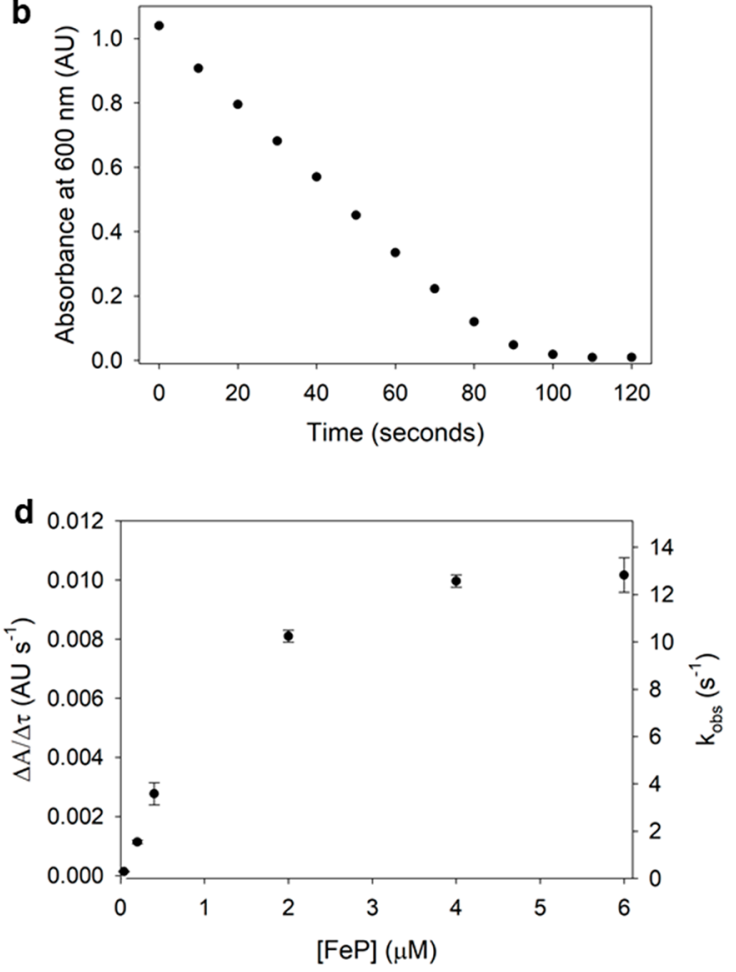

Figure 4. $\left[(\mathrm{SPr})_{2} \mathrm{~V}^{\bullet}\right]^{-}$as an electron donor for the spectrophotometric activity assay for nitrogenase under argon. (a) Spectrophotometric evidence of the oxidation of $\left[(\mathrm{SPr})_{2} \mathrm{~V}^{\bullet}\right]^{-}$by nitrogenase in activity assay buffer and $(\mathrm{b})$ time course at $606 \mathrm{~nm}$. (c) $k_{\mathrm{obs}}$ vs $\left[(\mathrm{SPr})_{2} \mathrm{~V}^{\bullet}\right]^{-}(\mathrm{black})$ and calculated $\left[(\mathrm{SPr})_{2} \mathrm{~V}^{\bullet}\right]^{-}$dimer concentration (red). (d) Plot of $k_{\mathrm{obs}} \mathrm{vs}[\mathrm{FeP}]$ measured spectrophotometrically at $600 \mathrm{~nm}$ in the presence of $0.5 \mathrm{mM}$ $\left[(\mathrm{SPr})_{2} \mathrm{~V}^{\bullet}\right]^{-}$. Conditions: $0.4 \mu \mathrm{M} \mathrm{MoFeP}, 6 \mu \mathrm{M} \mathrm{FeP}$ in activity assay buffer $(0.5 \mathrm{~mL} ; n=3)$, and cuvette path length of $0.2 \mathrm{~cm}$.

$$
k_{\mathrm{obs}}=\left(0.4463 \frac{i_{\mathrm{cat}}}{i_{\mathrm{p}}}\right)^{2} \frac{n F v C_{\mathrm{Med}}^{\mathrm{o}}}{R T C_{\mathrm{E}}^{\mathrm{o}} \times 2}
$$

where $k_{\mathrm{obs}}$ is the observed kinetic constant for substrate reduction, $i_{\text {cat }}$ is the current of the catalytic reaction, $i_{\mathrm{p}}$ is the peak current of the mediator in the absence of nitrogenase, $n$ is the number of electrons in the electrochemical reaction $(n=$ $1), F$ is Faraday's constant, $v$ is the scan rate, $C_{\text {Med }}^{o}$ is the mediator concentration, $R$ is the ideal gas constant, $T$ is the reaction temperature, and $C_{\mathrm{E}}^{\mathrm{o}}=C_{\mathrm{MoFeP}}^{\mathrm{o}}$ in the presence of an excess of $\mathrm{FeP}$.

A spectroscopic study similar to that described above was performed to test the nitrogenase activity at higher concentrations of $\left[(\mathrm{SPr})_{2} \mathrm{~V}^{*}\right]^{-}$. Panels a and $\mathrm{b}$ of Figure 4 show the spectra and time course at $600 \mathrm{~nm}$ in the presence of nitrogenase, respectively. No decrease in activity was observed with an increase in the concentration of $(\mathrm{SPr})_{2} \mathrm{~V}$ to $3 \mathrm{mM}$ (Figure $4 \mathrm{c})$. In addition, our studies revealed that $(\mathrm{SPr})_{2} \mathrm{~V}$ in its one-electron reduced form is prone to dimerize with an association constant of $841 \mathrm{M}^{-1}$ (Figure S5 and Figure 4c). This finding shows that $\left[(\mathrm{SPr})_{2} \mathrm{~V}^{\bullet}\right]^{-}$achieves high efficiency with nitrogenase, likely due to the additional negatively charged groups preventing interference in the nitrogenase catalytic cycle.

To confirm $\mathrm{N}_{2}$ reduction in the presence of $\left[(\mathrm{SPr})_{2} \mathrm{~V}^{\bullet}\right]^{-}$as an electron donor, $0.4 \mu \mathrm{M} \mathrm{MoFeP}$ and $6 \mu \mathrm{M} \mathrm{FeP}$ were added to the activity assay buffer containing $1 \mathrm{mM}\left[(\mathrm{SPr})_{2} \mathrm{~V}^{\bullet}\right]^{-}$under $\mathrm{N}_{2}$ in a sealed vial and left to react until all the reductant was consumed. The formation of $143 \mu \mathrm{M}$ ammonium was confirmed using a fluorometric assay. ${ }^{24}$
Previously described spectrophotometric activity assays for nitrogenase utilized sodium dithionite ${ }^{25}$ or titanium(III) citrate $^{26}$ as the electron donor. These methods are limited by the low stability and low extinction coefficients of these electron donors. For these methods, the measurement of nitrogenase activity still relies on the assays requiring the obligatory product quantification: $\mathrm{NH}_{3}$ by fluorometric assay and $\mathrm{H}_{2}$ by gas chromatography. Here, we tested $\left[(\mathrm{SPr})_{2} \mathrm{~V}^{\bullet}\right]^{-}$ as a stable and easy to prepare reductant for nitrogenase in a spectrophotometric activity assay. The assay was performed in a cuvette with a path length of $0.2 \mathrm{~cm}$ in the presence of 0.5 $\mathrm{mM}\left[(\mathrm{SPr})_{2} \mathrm{~V}^{\bullet}\right]^{-}$. The extinction coefficient was determined to be $9925 \mathrm{M}^{-1} \mathrm{~cm}^{-1}$ at $600 \mathrm{~nm}$. Figure $4 \mathrm{~d}$ shows the wellpronounced dependence of the catalytic rate constant on $\mathrm{FeP}$ concentration. The dependence of the nitrogenase reaction rate on $\mathrm{MoFeP}$ concentration was also studied spectrophotometrically and exhibits a linear relationship between the reaction rate and the concentration of MoFeP (see Figure S6). The lowest concentrations of nitrogenase proteins measured by this assay were $40 \mathrm{nM} \mathrm{FeP}$ and $20 \mathrm{nM} \mathrm{MoFeP}$ (see Figure S6). The sensitivity of the assay is $0.0074 \mathrm{~s}^{-1} \mu \mathrm{M}^{-1}$ for FeP (determined for $<0.4 \mu \mathrm{M} \mathrm{FeP}$, in the presence of $0.4 \mu \mathrm{M}$ $\mathrm{MoFeP}$ ) and $0.0266 \mathrm{~s}^{-1} \mu \mathrm{M}^{-1}$ for MoFeP (in the presence of 6 $\mu \mathrm{M} F e \mathrm{P})$. It is expected that utilization of $\left[(\operatorname{SPr})_{2} \mathrm{~V}^{\bullet}\right]^{-}$as a reductant for nitrogenase should facilitate many mechanistic and genetic engineering studies because it provides a fast and sensitive determination of nitrogenase activity. The application of $(\mathrm{SPr})_{2} \mathrm{~V}$ as an electrochemical mediator in bioelectrosynthetic $\mathrm{N}_{2}$ reduction is promising because, in contrast to methyl viologen, it shows a lower overpotential and allows the use of higher concentrations of the electrochemical mediator, which 
does not inhibit nitrogenase activity and may result in higher product formation rates.

\section{ASSOCIATED CONTENT}

\section{S Supporting Information}

The Supporting Information is available free of charge on the ACS Publications website at DOI: 10.1021/acs.biochem.9b00844.

General considerations, electrolysis of viologens, determination of extinction coefficients, influence of the dimerization of viologens on their formal redox potential, determination of the $\left[(\mathrm{SPr})_{2} \mathrm{~V}^{\bullet}\right]^{-}$dimerization constant, and MoFeP concentration dependence (Figures $\mathrm{S} 1-\mathrm{S} 6)$ (PDF)

\section{Accession Codes}

MoFeP, UniProtKB P07328 and P07329; FeP, UniProtKB P00459.

\section{AUTHOR INFORMATION}

\section{Corresponding Authors}

*E-mail: a.badalyan@usu.edu.

*E-mail: lance.seefeldt@usu.edu.

\section{ORCID $\odot$}

Artavazd Badalyan: 0000-0002-6933-6181

Zhi-Yong Yang: 0000-0001-8186-9450

Lance C. Seefeldt: 0000-0002-6457-9504

\section{Author Contributions}

A.B. conceived the idea of the project and designed and performed all experiments. A.B. led the data interpretation and analysis in consultation with L.C.S. Z.-Y.Y. isolated and purified MoFeP. Z.-Y.Y. and A.B. isolated and purified FeP. J.L., B.H., and M.H. synthesized $(\mathrm{SPr})_{2} \mathrm{~V}$ and $\left[(\mathrm{NPr})_{2} \mathrm{~V}\right]^{4+}$ under the supervision of T.L.L. A.B. and L.C.S. wrote the manuscript.

\section{Funding}

All spectrophotometric and electrochemical studies were supported by the U.S. Department of Energy, Office of Science, Basic Energy Sciences, Physical Biosciences (DESC0010687). T.L.L. acknowledges the National Science Foundation (Career Award, Grant 1847674) for supporting the synthesis of viologen compounds. B.H. and M.H. are grateful for China CSC Abroad Studying Fellowships to support their Ph.D. study program at Utah State University.

\section{Notes}

The authors declare no competing financial interest.

\section{REFERENCES}

(1) Tezcan, F. A., Kaiser, J. T., Mustafi, D., Walton, M. Y., Howard, J. B., and Rees, D. C. (2005) Nitrogenase complexes: multiple docking sites for a nucleotide switch protein. Science 309, 1377-1380.

(2) Spatzal, T., Aksoyoglu, M., Zhang, L., Andrade, S. L. A., Schleicher, E., Weber, S., Rees, D. C., and Einsle, O. (2011) Evidence for interstitial carbon in nitrogenase FeMo cofactor. Science 334, 940940.

(3) Yang, Z.-Y., Ledbetter, R., Shaw, S., Pence, N., TokminaLukaszewska, M., Eilers, B., Guo, Q., Pokhrel, N., Cash, V. L., Dean, D. R., Antony, E., Bothner, B., Peters, J. W., and Seefeldt, L. C. (2016) Evidence that the $\mathrm{Pi}$ release event Is the rate-limiting step in the nitrogenase catalytic cycle. Biochemistry 55, 3625-3635.

(4) Pence, N., Tokmina-Lukaszewska, M., Yang, Z.-Y., Ledbetter, R. N., Seefeldt, L. C., Bothner, B., and Peters, J. W. (2017) Unraveling the interactions of the physiological reductant flavodoxin with the different conformations of the Fe protein in the nitrogenase cycle. J. Biol. Chem. 292, 15661-15669.

(5) D'Eustachio, A. J., and Hardy, R. W. F. (1964) Reductants and electron transport in nitrogen fixation. Biochem. Biophys. Res. Commun. $15,319-323$

(6) Ware, D. A. (1972) Nitrogenase of Klebsiella pneumoniae: interaction with viologen dyes as measured by acetylene reduction. Biochem. J. 130, 301-302.

(7) Seefeldt, L. C., Hoffman, B. M., Peters, J. W., Raugei, S., Beratan, D. N., Antony, E., and Dean, D. R. (2018) Energy transduction in nitrogenase. Acc. Chem. Res. 51, 2179-2186.

(8) Yang, Z.-Y., Khadka, N., Lukoyanov, D., Hoffman, B. M., Dean, D. R., and Seefeldt, L. C. (2013) On reversible $\mathrm{H}_{2}$ loss upon $\mathrm{N}_{2}$ binding to FeMo-cofactor of nitrogenase. Proc. Natl. Acad. Sci. U. S. A. $110,16327-16332$.

(9) Lukoyanov, D., Khadka, N., Yang, Z.-Y., Dean, D. R., Seefeldt, L. C., and Hoffman, B. M. (2016) Reductive elimination of $\mathrm{H}_{2}$ activates nitrogenase to reduce the $\mathrm{N} \equiv \mathrm{N}$ triple bond: characterization of the $\mathrm{E}_{4}(4 \mathrm{H})$ Janus intermediate in wild-type enzyme. J. Am. Chem. Soc. 138, 10674-10683.

(10) Oughli, A. A., Conzuelo, F., Winkler, M., Happe, T., Lubitz, W., Schuhmann, W., Rüdiger, O., and Plumeré, N. (2015) A Redox Hydrogel Protects the $\mathrm{O}_{2}$-Sensitive $[\mathrm{FeFe}]$-Hydrogenase from Chlamydomonas reinhardtii from Oxidative Damage. Angew. Chem., Int. Ed. 54, 12329-12333.

(11) King, P. W., Posewitz, M. C., Ghirardi, M. L., and Seibert, M. (2006) Functional Studies of [FeFe] Hydrogenase Maturation in an Escherichia coli Biosynthetic System. J. Bacteriol. 188, 2163-2172.

(12) Tatsumi, H., Takagi, K., Fujita, M., Kano, K., and Ikeda, T. (1999) Electrochemical study of reversible hydrogenase reaction of Desulfovibrio vulgaris cells with methyl viologen as an electron carrier. Anal. Chem. 71, 1753-1759.

(13) Kuwabata, S., Tsuda, R., and Yoneyama, H. (1994) Electrochemical conversion of carbon dioxide to methanol with the assistance of formate dehydrogenase and methanol dehydrogenase as biocatalysts. J. Am. Chem. Soc. 116, 5437-5443.

(14) Enoch, H. G., and Lester, R. L. (1975) The purification and properties of formate dehydrogenase and nitrate reductase from Escherichia coli. J. Biol. Chem. 250, 6693-6705.

(15) Shin, W., Lee, S. H., Shin, J. W., Lee, S. P., and Kim, Y. (2003) Highly Selective Electrocatalytic Conversion of $\mathrm{CO}_{2}$ to $\mathrm{CO}$ at -0.57 $\mathrm{V}$ (NHE) by Carbon Monoxide Dehydrogenase from Moorella thermoacetica. J. Am. Chem. Soc. 125, 14688-14689.

(16) Hadj-Saïd, J., Pandelia, M.-E., Léger, C., Fourmond, V., and Dementin, S. (2015) The Carbon Monoxide Dehydrogenase from Desulfovibrio vulgaris. Biochim. Biophys. Acta, Bioenerg. 1847, 15741583.

(17) Badalyan, A., Yang, Z.-Y., and Seefeldt, L. C. (2019) A Voltammetric Study of Nitrogenase Catalysis Using Electron Transfer Mediators. ACS Catal. 9, 1366-1372.

(18) Milton, R. D., Cai, R., Abdellaoui, S., Leech, D., De Lacey, A. L., Pita, M., and Minteer, S. D. (2017) Bioelectrochemical Haber-Bosch Process: An Ammonia-Producing $\mathrm{H}_{2} / \mathrm{N}_{2}$ Fuel Cell. Angew. Chem., Int. Ed. 56, 2680-2683.

(19) Geraskina, M. R., Dutton, A. S., Juetten, M. J., Wood, S. A., and Winter, A. H. (2017) The Viologen Cation Radical Pimer: A Case of Dispersion-Driven Bonding. Angew. Chem., Int. Ed. 56, 9435-9439.

(20) DeBruler, C., Hu, B., Moss, J., Liu, X., Luo, J., Sun, Y., and Liu, T. L. (2017) Designer Two-Electron Storage Viologen Anolyte Materials for Neutral Aqueous Organic Redox Flow Batteries. Chem. 3, 961-978.

(21) DeBruler, C., Hu, B., Moss, J., Luo, J., and Liu, T. L. (2018) A Sulfonate-Functionalized Viologen Enabling Neutral Cation Exchange, Aqueous Organic Redox Flow Batteries toward Renewable Energy Storage. ACS Energy Lett. 3, 663-668.

(22) Lanzilotta, W. N., Ryle, M. J., and Seefeldt, L. C. (1995) Nucleotide Hydrolysis and Protein Conformational Changes in Azotobacter vinelandii Nitrogenase Iron Protein: Defining the Function of Aspartate 129. Biochemistry 34, 10713-10723. 
(23) Braaksma, A., Haaker, H., Grande, H. J., and Veeger, C. (1982) The Effect of the Redox Potential on the Activity of the Nitrogenase and on the Fe-Protein of Azotobacter vinelandii. Eur. J. Biochem. 121, 483-491.

(24) Barney, B. M., Igarashi, R. Y., Dos Santos, P. C., Dean, D. R., and Seefeldt, L. C. (2004) Substrate interaction at an iron-sulfur face of the FeMo-cofactor during nitrogenase catalysis. J. Biol. Chem. 279, 53621-53624.

(25) Ljones, T., and Burris, R. H. (1972) Continuous spectrophotometric assay for nitrogenase. Anal. Biochem. 45, 448452.

(26) Seefeldt, L. C., and Ensign, S. A. (1994) A Continuous, Spectrophotometric Activity Assay for Nitrogenase Using the Reductant Titanium(III) Citrate. Anal. Biochem. 221, 379-386. 